\title{
Research on the Development Strategy of Accordion Culture and Museum Industry in Liuxing Street, Yining City*
}

\author{
Yan Li \\ Faculty of Biology and Geographical Sciences \\ Yili Normal University \\ Yining, China
}

\author{
Youwen Wang \\ Faculty of Marxism \\ Yili Normal University \\ Yining, China
}

\author{
Jianhui Yun** \\ Science and Technology Management Department \\ Yunnan Agricultural University \\ Kunming, China \\ **Corresponding Author
}

\begin{abstract}
Liuxing Street in Yining City is traditionally the residence of Russian immigrants and their descendants. The Bayan art of Russian accordion has been inherited here. Alexander private accordion museum has certain popularity, but the accordion cultural industry in Yining City has not been greatly developed. Based on the field survey, this paper discusses how to promote the accordion culture and tourism industry to become a new cultural and tourism integration highlight in Liuxing Street, and promote Yining City to become a tourism destination city and a strong tourism city.
\end{abstract}

Keywords-Liuxing street; accordion culture and museum industry; culture and tourism integration

\section{INTRODUCTION}

Since its entry into Yili, Russian Bayan art has been integrated with the accordion art of all ethnic groups in Yili and the musical instrument performance art of other ethnic groups, forming a Chinese "Russian Bayan art" with the characteristics of Yili ethnic culture in Xinjiang. Liuxing Street is a Russian ethnic community where accordion culture is inherited and spread. Alexander accordion museum is a representative of the concentrated display of accordion culture, which has a high reputation at home and abroad.

*Fund: The National Social Science Fund Project of China "Study on the International tourism Cooperation mode of Grassland Culture between China and Kazakhstan under the Guidance of Shanghai Cooperation Organization"(12BJY129); Humanities and Social sciences Fund Project of the Ministry of Education "A Study on 'One road' and 'One belt' International Tourism Linkage Strategic Mode and Cooperation Mechanism between South and West" (17YJA790046); Open Social Science Fund Project of Research Center for Cooperative Development between Xinjiang and Neighboring Countries of Yili Normal University "Research on the Construction and Function of China and Central Asia's Grassland Culture International Tourism Circle under the Background of 'the Belt and Road' Initiative (2016ZBGJZD001) and "Research on the Development Path of Xinjiang Tourism Distributing Center Oriented to 'the Belt and Road' (2017ZBGJZD001)
Based on the field survey, this paper studies the current status of the integration of culture and tourism of accordion culture and museum industry in Liuxing street, Yining City, explores advantages of cultural tourism integration development of culture and museum industry in Yining City, and puts forward integrated development strategies of culture and tourism for accordion culture and museum industry in Yining City.

\section{RESEARCH STATUS}

Traditionally, Liuxing Street is a Russian ethnic community where accordion culture is inherited and spread. Alexander accordion museum is a representative of the concentrated display of accordion culture, which has a high reputation at home and abroad, but less theoretical research On CNKI, we searched for several theme words such as "Alexander accordion Museum" and "Yili accordion culture", only one document was collected. Ma Xi (2012) studied the development and characteristics of Yili accordion music culture. Taking time as the axis, she systematically introduced the origin, development, characteristics and current situation of accordion education of Yili accordion culture. She pointed out that there are various kinds of accordion instruments, accordion music types and styles, accordion music performance forms and accordion music existence range in Yili.

Although some scholars mentioned Alexander and its accordion collection in the article, the research on "Alexander accordion Museum" has not been carried out at present, nor has it involved "the integration and development of culture and tourism of accordion in Yining City ". Therefore, the in-depth and systematic study of this issue is not only the need of the practice of cultural tourism integration in Yili Prefecture and Yining City, but also the need of academic research on this issue. 
including China, Russia, Germany, Italy, Ukraine, Belarus, Poland, France, Britain, South Korea and so on, with the help of his family and income. The oldest accordion has been manufactured in 1800, 219 years ago. It has been refined in Alexander. It can still be played under Alexander's careful care (see "Table I"). Alexander has collected more than 5000 Chinese and foreign musical instruments, production tools and daily necessities of Yili in the past, including Chinese and foreign orchestral instruments, clocks, radios, cameras and production tools used by Yili people in Xinjiang in the past. It has become the only world accordion collection in Xinjiang and even the whole country, which is completely formed by private collection, which has become a private accordion museum with certain popularity at home and abroad.

\begin{tabular}{|l|l|l|l|l|l|}
\hline \multicolumn{1}{|c|}{ Country } & $\begin{array}{c}\text { Total quantity } \\
\text { (shelf) }\end{array}$ & $\begin{array}{l}\text { Brand quantity } \\
\text { (species) }\end{array}$ & \multicolumn{1}{|c|}{ Country } & $\begin{array}{c}\text { Total quantity } \\
\text { (shelf) }\end{array}$ & $\begin{array}{c}\text { Brand quantity } \\
\text { (species) }\end{array}$ \\
\hline China & 126 & 8 & Ukraine & 67 & 7 \\
\hline Russia & 524 & 25 & Belarus & 85 & 6 \\
\hline France & 2 & 1 & South Korea & 5 & 1 \\
\hline Britain & 4 & 1 & Poland & 5 & 1 \\
\hline U.S.A & 2 & 1 & Austria & 2 & 1 \\
\hline Italy & 36 & 5 & Czechoslovakia & 2 & 1 \\
\hline Germany & 139 & 7 & 1 & 1 \\
\hline
\end{tabular}

${ }^{\text {a. }}$ Source: provided by Alexander Accordion Museum, Liuxing street, Yining City, Yili Prefecture, July 2019.

Over the past 30 years, with the unremitting pursuit, careful management and joint efforts of the whole family, Alexander accordion Museum has grown from small to large, from unknown to well-known, with more and more visitors and tourists, playing an increasingly social role in promoting
Yili folk culture, accordion culture and Liuxing street culture. According to incomplete statistics, the Alexander private accordion Museum received more than 10500 visitors from 2013 to 2018 (see "Table II")

TABLE II. STATISTICS OF THE NUMBER OF Visitors RECEIVED By ALEXANDER PRIVATE ACCORDION MUSEUM FROM 2013 TO 2018

\begin{tabular}{|c|c|c|c|c|c|c|c|}
\hline Year & $\mathbf{2 0 1 3}$ & $\mathbf{2 0 1 4}$ & $\mathbf{2 0 1 5}$ & $\mathbf{2 0 1 6}$ & $\mathbf{2 0 1 7}$ & $\mathbf{2 0 1 8}$ & Total \\
\hline Annual reception & 800 & 1200 & 1600 & 2000 & 2100 & 2800 & 10500 \\
\hline \multicolumn{8}{|c|}{ Note: the data of the above years are calculated on a monthly average basis and are incomplete statistics. } \\
b. Source: provided by Alexander accordion Museum, Liuxing street, Yining City, Yili Prefecture, July 2019.
\end{tabular}

With the great attention and active help of Yining City municipal Party committee, municipal government and municipal intangible cultural heritage protection center, in August 2013, Zazulin. Alexander successfully applied for the representative work of intangible cultural heritage of Xinjiang Uygur Autonomous Region, Russian Bayan art, and became the inheritor of Russian Bayan art. In order to build Liuxing Street into a high-quality folk culture tourist area in Yining City and even in Yili Prefecture, as well as the Alexander accordion Museum into the intangible cultural heritage protection base of Russian Bayan art, under the coordination of Yining City municipal Party committee, municipal government and cultural tourism department, Alexander accordion collection hall has been built, and 692 accordions have been transported and placed in the accordion collection hall by the inheritor's family. Alexander accordion collection hall has become a platform for the collection and preservation of related physical objects and the protection and inheritance of Bayan art, an intangible cultural heritage project of the autonomous region. The rest of the collections are still stored in two accordions and other collections exhibition rooms in their own houses. According to incomplete statistics, only 7927 experts, scholars, guest visitors and tourists from September 2018 to July 2019 have been received by the folk culture exhibition hall of Liuxing Street in Yining City. 


\section{ADVANTAGES OF CULTURAL TOURISM INTEGRATION DEVELOPMENT OF CULTURE AND MUSEUM INDUSTRY IN YINING CITY}

\section{A. A Clearer Position of Liuxing Street in the Cultural Industry Planning of Yining City}

Since 2018, the Liuxing Street upgrading and reconstruction plan has been announced, positioning "Silk Road Flower City · colorful Yining City", adhering to the working principle of "characteristics as the key, culture as the soul", relying on the unique urban pattern of Liuxing Street, Russian customs and the advantages of multi-cultural intersection of human resources, comprehensively implement the comprehensive upgrading and transformation project with the core content of improving the living environment of the residents, highlighting the essence of the characteristic culture of the block, improving the functional facYilities of tourism service, and improving the management and operation mode. Liuxing Street has gradually formed a virtuous cycle of attracting business by street, leading business by street, prospering tourism by business, and promoting prosperity by tourism. It has built a leisure tourism block with tourism enriching people, benefiting people, sharing the beautiful life of rural city with residents and tourists, ensuring the comprehensive protection, rational development and sustainable utilization of unique historical and cultural and natural ecological resources, and maximizing the harmony of economic and social benefits, ecological and cultural effects.

\section{B. A Clear Understanding of the Important Functions of Accordion Culture and Museum Industry in the Development of Cultural Tourism in Liuxing Street}

In recent years, the integration of culture and museum resources and tourism is a hot issue in the field of culture and museum development at home and abroad. It is also a breakthrough and growth point to promote the innovation and development of local cultural tourism. As a beautiful business card of Liuxing Street, Alexander and his accordion museum are well-known at home and abroad. Alexander, with his low income, has bought more than 1000 accordions from various countries, ages, types and forms, which is unique in Xinjiang. These rich collections can promote tourism industry through culture and museum. Both Alexander and the local government have a clearer understanding of this.

\section{C. "The Belt and Road" Initiative Provides a Good} International Environment for the integration of the Accordion Culture Museum Industry and the Liuxing Street Tourism Area, Making the Liuxing Street a Unique Scenic Spot of Yili International Tourism Valley

Accordion is a musical instrument popular along "the Belt and Road", especially in Europe, Russia, Western and Central Asian countries, and also has accordion culture with its own characteristics. The implementation of "the Belt and Road" initiative and international cooperation has made accordion culture a barrier free cultural fusion channel for all countries to connect, communicate and exchange with each other. The popularization of accordion culture and the uniqueness of space, time and background of the accordion Museum in Liuxing Street are powerful help for Liuxing Street to become a unique scenic spot of Yili international tourism Valley, and provide an international cultural tourism cooperation environment for the integration and development of the cultural and tourism industry in Liuxing Street.

\section{Supportingt Xinjiang to Boost the Development of Liuxing Street Accordion Culture}

Nanjing is a counterpart support unit for Yining City. In September 2017, Nanjing Federation of literary and art and Yining City Federation of literary and art signed a agreement of intent to establish a friendly unit cooperation. Based on the story of accordion player Alexander, they created a radio play "The sound of the accordion is far away ". The play has been broadcast on the voice of literature and art of the central people's radio, Jiangsu radio and television, Xinjiang radio and television, which has improved the popularity of Alexander accordion museum, so many foreign tourists from other places come here. The "Yili accordion band" went to Nanjing for publicity and performance, and gained a sensational effect, which attracted wide attention of Nanjing citizens. Later, Wang Yang, chairman of the CPPCC National Committee, warmly received the performance in Beijing and renamed the band "Yili Liuxing Street national unity accordion band". The melodious music brings the name of Liuxing Street to all parts of the country, and improves the popularity and attraction of Liuxing Street among tourists from north to south of China and all over the world.

\section{SELECTION OF INTEGRATED DEVELOPMENT STRATEGIES OF CULTURE AND TOURISM FOR ACCORDION CUlTuRE AND Museum INDUSTRY IN YINING CITY}

\section{A. International Tourism Cooperation and Innovation Strategy}

The innovation strategy of international tourism cooperation refers to an operation paradigm of innovating tourist attractions and tourism products by relying on the distinctive characteristics of accordion culture as the soul and tie, based on " the Belt and Road" international tourism cooperation mechanism to develop the tourism market.

1) Building accordion cultural tourism park: Alexander accordion museum and accordion culture in Liuxing Street are well known at home and abroad. Accordion culture from the upstream production and manufacturing industry, the midstream sales industry, the downstream training industry and performing arts industry have transnational and cross regional characteristics. With the help of the accordion and the culture foundation of accordion culture as a link and breakthrough point, the accordion culture tourism park with theme accordion can be designed in Liuxing Street, and the various international tourist products, such as accordion culture landscape, accordion culture hotel, accordion culture 
tourism commodity, and accordion cultural tourism logo, etc. are implanted into it to attract domestic and foreign tourists who love music and accordion culture.

2) Relying on "The Belt and Road" to develop international accordion culture exhibition tourism: Accordion is a musical instrument popularized by the countries along "the Belt and Road" and the related industries are relatively developed. For example, accordion manufacturing, sales, training and performing industries have also produced a wide range of accordion culture lovers. With the accordion as the medium, the accordion related industries and enthusiasts are invited to develop the international exhibition with the accordion culture as the theme, which will certainly drive the development of other industries. For example, on the basis of Alexander Accordion Museum and Tacheng Museum in Yining City, Yili Prefecture and Central Asian countries jointly hold China Central Asia International Accordion Industry Expo, China Central Asia International Accordion Industry Symposium, China Central Asia International Accordion Art University in each year in Yining City, Tacheng city and Almaty City, Kazakhstan. Accordion entrepreneurs, musicians, artists, expert professors, performers and accordion enthusiasts from the Eurasian Economic Union countries and member countries of Shanghai Cooperation Organization were invited to attend the conferences, so as to improve and expand the international tourism level and scale efficiency of Yili Prefecture and Yining City.

3) Rationalizing the management system and operation mode, and create a national tourist attraction by combining single building with overall promotion: Only under the guidance of the characteristic principle can the planned tourism project have new ideas, have broad market and strong attraction, and produce sensational effect and scale effect. Among the more than 1000 accordions collected by Alexander folk accordion museum, there are 998 accordions from Eurasia countries, accounting for $99.8 \%$ of the total accordion collection, which is extremely rare in China. Many years' practice has proved that Alexander accordion museum and its collection of more than 1000 accordions in the whole Liuxing block, especially the collection of accordions from various Eurasian countries, are the most important tourist attractions at present. The attraction of Alexander accordion museum to tourists is far greater than that of Liuxing Street folk culture exhibition hall. Therefore, Yining City municipal government, cultural tourism department, Liuxing street community and Scenic Area Management Committee must adhere to the new concept of "marketization of cultural and tourism resources", take the supply side structural reform of cultural and tourism industry as the innovation power, make full use of the advantages of 998 accordions collected by Alexander accordion museum in Eurasia, firstly create, declar and establish "Yining City Eurasian Accordion Cultural Expo Park" in accordance with the national 2A level scenic spot standards in the long process of the reconstruction of Liuxing street to create a tourist attraction. The current folk culture exhibition hall and Alexander's collection of more than 6000 National musical instruments of various countries and previous living and production objects will be opened separately as a special exhibition hall of the cultural and Expo Park. In order to activate the resources and assets of folk tourism attractions and innovate cultural and museum tourism products, the mode of "private public assistance, joint-stock cooperation, market operation" is implemented, and the tickets for scenic spots are legally collected to increase the family income of Alexander and reflect the great economic value of the collection of Alexander accordion Museum. In the process of "Yining City Eurasian Accordion Culture and Expo Park" attracting a large number of tourists, gradually increase the total number of tourists in Liuxing street, create the basic conditions of tourism elements for building Liuxing Street folk culture tourism area into a national $3 \mathrm{~A}$ level or above tourist attraction in two to three years, realize the good cultural and tourism integration effect and tourism economic development objective of "a bridge between culture and Museum, singing in tourism, people to people and win-win economy and trade " in Yining City.

\section{B. Smart Tourism Strategy of Integration of Culture and Tourism}

The smart tourism strategy of integration of culture and tourism refers to refers to a compound operation mode which makes full use of the inherent characteristics of culture and tourism as resources, carriers, motive forces and goals, applies the technical means of smart tourism to develop tourism routes, scenic spots and tourism products, integrates culture and tourism, so that tourists can naturally obtain multiple benefits of economy, society and ecological environment in the process of obtaining high-grade experience tourism.

1) Seizing the opportunity of national integration of culture and tourism and realize the integration of culture and tourism in the whole region: In the development of cultural tourism, Yining City municipal government, cultural tourism department and Liuxing street community should adhere to the principles that culture and tourism are mutual resources, carriers, motive forces, goals and win-win results, so as to make Liuxing Street folk culture tourism area develop a unique way of tourism industry development based on Russian culture and accordion culture. On the basis of "Yili national unity accordion band" and Alexander accordion museum, guide all kinds of accordion social organizations, accordion teaching units, accordion training institutions, accordion enthusiasts and other efforts to popularize and improve the level of accordion cultural industry in Yili Prefecture, and take the initiative to develop the accordion cultural art and accordion for Yining City and Liuxing street. At the same time, it actively provides a platform for international and domestic cooperation and 
a smart tourism information platform attracting the expansion of domestic tourists and expanding "the Belt and Road" international tourism market. It makes full use of the strength of universities, scientific research institutes and tourism enterprises, jointly builds a base of government, industry, education and research, and integrates the tourism marketing consultation, tourism information service, tourism transportation, board and lodging service, tourism, culture, entertainment and leisure service and other resources of Yining City with new concepts and mechanisms to realize the diversified services of cultural tourism elements and promotion in Liuxing Street tourist area, and the seamless all-weather service of "one mobile scenic area" for tourists.

\section{Overall Planning and Construction Strategy of All-for- one Tourism}

The overall planning and construction strategy of all-forone tourism refers to a comprehensive operational paradigm of taking a certain region as a complete tourism destination, taking tourism as the dominant leading industry, unifying planning, integrating resources, promoting the integration of various industries and fields, enhancing the new functions of tourism development, driving the overall development of other industries, better meeting the demand of tourism consumption, and building a new type of tourism area with overall planning, coordination and integrated development. In the development and construction of Yining City tourism industry and Liuxing Street folk culture tourism area, it grasps the opportunity of all-for-one tourism development in Yili Prefecture, gives full play to the conditions and advantages of all industries in Yili prefecture to advance allfor-one tourism, and works together to promote the development of tourism in Yining City and Liuxing Street folk culture tourism area.

1) Adhering to the plan as the guide and optimize the overall development pattern: The planning and design of all-for-one tourism project in Liuxing Street folk culture tourism area of Yining City should adhere to the six principles of "maximum benefit, marketization, characteristics, feasibYility, operabYility and sustainable development". It is necessary to establish a comprehensive planning sub parent system that links tourism development with block development, industrial agglomeration, improvement of people's livelihood, environmental protection and other factors.

2) Building Liuxing Street into a miniature all-for-one tourism scenic spot in Yili Prefecture's all-for-one tourism demonstration area: Efforts should be made to connect with the surrounding environment and resources, information exchange, smooth traffic and people's feelings, and take the road of regional cooperation and complementary and winwin advantages of resources. It adheres to the publicity and marketing as the starting point, and strives to build a tourism brand. it will jointly create a marketing brand with "bright spots and selling points", innovates tourism marketing means, improves management and service mechanism, enhances the reputation of Yili's tourism 
business card, and promotes all the members of Liuxing street community to participate in the construction of the tourism area.

\section{CONCLUSION}

Alexander is the inheritor of "Russian Bayan art", a district level intangible cultural heritage. $\mathrm{He}$ and the accordion museum are well-known at home and abroad, which is an attractive tourism resource for the development of tourism in Liuxing street, Yining City. Yining City is an important node on "the Belt and Road", where accordion culture has been widely circulated in various countries. With Alexander and his accordion Museum and Liuxing Street accordion band as the media, we will communicate the cultural exchanges between China and the countries along the line, especially the Central Asian countries, promote the integration of the culture and tourism of the Liuxing Street historical and cultural block, and launch more cultural tourism products that meet the needs of tourists. It is of great significance to enhance the popularity of Liuxing Street, to realize the function of Yining City tourist destination distribution center, to increase employment and to improve the income of residents and government.

\section{REFERENCES}

[1] Wang Kunxin, Evaluation and Development of Tourism Resources. Beijing, Tsinghua University Press. 2010. (in Chinese)

[2] Ma Yaofeng, Yanyan,Wei Fengqun, Tourism Planning. Beijing: China Renmin University Press. 2011. (in Chinese)

[3] Lin Jiajia, Research on the Protection Division of Liuxing Street in Yili City from the Perspective of Place. Mianyang: Southwest University. 2015. (in Chinese)

[4] Wulang, Pan Yonggang, Retaining the City in Modern Urban Life Strategies to perspective and develop Liu Xing Jie historic distractive in Yinin.Journal of Xi'an University of Architecture and Technology, 2012,vol.XXXI,pp. 54-59.(in Chinese)

[5] Qiu Limei, Wangce, and Cheng Yusong, The Renovation of Xinjiang Historical and cultural block - A Case Study from Yining Liuxing Street. Chinese Horticulture Abstracts,2014,pp.114-115+128.(in Chinese)

[6] Caoxu, The Study on street space form of Yining Liu Xing Jie ,Xin Jiang.Modern Decoration(Theory), 2015, pp. 54. (in Chinese)

[7] Maqian, The development and characteristics of Yili Accordion Music Culture. Journal of Xinjiang University of the Arts, 2012, vol.X, pp.32-35. (in Chinese)

[8] General Office of the State Council, Guidance on Promoting the Development of All-for-one Tourism. Avalliable at http://www.gov.cn/zhengce/content/. 2018-03-22 .(in Chinese)

[9] Hu Yuelong, Douqun, A New Concept of Development for All-forone Tourism. China Tourism News.2015-10-26.(in Chinese)

[10] Li Jinzao, A Bright Future for All-for-one Tourism. Avalliable at https://www.mct.gov.cn/.2016-02-07 .(in Chinese)

[11] Xiong Gaizhi, Content and Future of Smart Tourism Construction. Information China, 2013, pp. 93-95. (in Chinese) 